\title{
AEROSOL JET DIRECT WRITING POLYMER-THICK-FILM RESISTORS FOR PRINTED ELECTRONICS
}

\author{
James Q. Feng, Anthony Loveland, and Michael J. Renn \\ Optomec, Inc. \\ St. Paul, MN, USA
}

\begin{abstract}
To improve performance and reduce size of printed-circuit board (PCB) in electronics industry, embedding discrete components within a board substrate has been an effective approach by reducing solder joints and their associated impedance mismatching, inductive reactance, etc. With its unique capabilities for non-contact precision material deposition, the Aerosol Jet ${ }^{\circledR}$ direct-write technology has been enabling additive manufacturing of fine-feature electronics conformally onto flexible substrates of complicated shapes. The CAD/CAM controlled relative motions between substrate and print head allows convenient adjustment of the pattern and pile height of deposited material at a given ink volumetric deposition rate. To date in the printed electronics industry, additively printing embedded polymer-thick-film (PTF) resistors has mostly been done with screen printing using carbon-based paste inks. Here we demonstrate results of Aerosol Jet ${ }^{\circledR}$ printed PTF resistors of resistance values ranging from $\sim 50 \Omega$ to $>1 \mathrm{k} \Omega$, adjustable (among several variable parameters) by the number of stacked layers (or print passes with each pass depositing a fixed amount of ink) between contact pads of around $1 \mathrm{~mm}$ apart with footprint line typically $<0.3 \mathrm{~mm}$. In principle, any ink material that can be atomized into fine droplets of 1 to 5 microns can be printed with the Aerosol Jet ${ }^{\circledR}$ system. However, the print quality such as line edge cleanliness can be significantly influenced by ink rheology which involves solvent volatility, solids loading, and so on. Our atomizable carbon ink was made by simply diluting a screen printing paste with a compatible solvent of reasonable volatility, which can be cured at temperatures below $200^{\circ} \mathrm{C}$. We show that Aerosol Jet ${ }^{\circledR}$ printed overlapping lines can be stacked to large pile height (to reduce the resistance value) without significant increase of line width, which enables fabricating embedded resistors with adjustable resistance values in a limited footprint space.
\end{abstract}

Key words: Printed electronics, Aerosol Jet ${ }^{\circledR}$ printing, directwrite technology, embedded PTF resistors.

\section{INTRODUCTION}

Electronic designers nowadays are facing two challenging demands for various applications: miniaturization and increased functionality. To satisfy these seemingly opposed requirements, reducing the number of mounted components - and thus solder joints-in PCB designs becomes an attractive approach by directly printing passive components such as embedded resistors into the circuit. This approach can also potentially increase the reliability, such as "mean time between failures" (MTBF), while reducing the circuit board size. To improve performance and reduce size of printed-circuit board (PCB) in electronics industry, embedding discrete components within a board substrate has been an effective approach by reducing solder joints and their associated impedance mismatching, inductive reactance, etc. Minimizing electrical path lengths is usually desirable to reduce parasitic effects, load fluctuations and noise in high-frequency circuits [1].

Embedded components can be categorized as passives (or passive devices such as resistors, capacitors, inductors, transformers, etc. which are incapable of introducing net energy into the circuit or increasing the power of a signal) and actives (or active devices such as transistors, tunnel diodes, etc.). Majority of the components in electrical circuits are usually passives (also referred to as "glue components") [1]. Therefore, embedded capacitance and resistance have attracted most attentions.

There are different approaches to fabricating embedded resistors (also known as integral resistors) in PCBs. One is the "thin film" method that stacks thin uniform and dense layers (having thickness $<0.4 \mu \mathrm{m}$ ) of resistive materials, by vacuum deposition (sputtering) or electro-chemical plating, onto the copper foil in the substrate that is then subtractive processed with laser trimming or laminated photoresist patterning and etching. The most common materials for thin-film resistors are alloys of Nickel and Chromium (Nichrome), having resistivity values around $100 \mu \Omega \mathrm{cm}$. The resistance value of thin-film resistors is mainly controlled by the film thickness, in a range of $0.2 \Omega$ to $20 \mathrm{M} \Omega$. The thin-film resistors are more precise, stable even at high frequencies with low temperature coefficient, but at high fabrication cost often only suitable for high-end products with relatively low volumes. Another method involves additive printing to produce "thick film" patterns (often having thickness $>10 \mu \mathrm{m})$ of resistive materials, which becomes more popular for (relatively) low manufacturing cost, high power rating, and wide range of resistance values.

Screen printing has been the most common method for fabricating the thick-film resistors as well as other passives [2]. Some thick-film resistive inks consist of a glassy frit binder, a carrier of organic solvent system with plasticizers, and oxides of ruthenium, iridium and rhenium---referred to as a cermet (ceramic - metallic). 
Although the printed ceramic-metallic resistors offer generally satisfactory performance, their high sintering temperatures (usually $\sim 800^{\circ} \mathrm{C}$ ) exclude applications with plastic and other temperaturesensitive substrates. Thus, polymer thick film (PTF) resistive materials, consisting of carbon powders with polymer chains for curing in ovens at temperatures under $200^{\circ} \mathrm{C}$, were developed and made commercially available often as paste inks for screen printing [3]. With a mesh that allows ink to penetrate and ink-blocking stencil mask of a given pattern, screen printing is capable of repeatedly producing thick-film resistors of fixed geometry at high speed [4]. However, it is usually restricted for printing on planar surfaces and would not be cost-effective for small-batch or oneof-a-kind type of pattern printing due to the expense of creating patterned stencil.

In contrast, the Aerosol Jet巴 (AJ) printing (as a direct-write technology) entails a maskless material deposition process without screen or stencil. It deposits ink materials in a form of highspeed mist stream consisting of ink droplets of 1 to $5 \mu \mathrm{m}$ with a long standoff between nozzle and substrate [5, 6]. With such a noncontact fashion, ink materials can be deposited onto not only planar substrates but also substrates of complex 3D shapes, when the relative motion of substrate with respect to the deposition nozzle is coordinated with a motion control system driven by the toolpath generated with a CAD-CAM software interface (Figure 1).

In this paper, we demonstrate an $\mathrm{AJ}$ direct-write process for fabrication of PTF resistors with resistance values around $100 \Omega$ using an ink made by diluting a carbon paste for screen-printing (i.e., Asahi PTF carbon paste TU-10S) with a compatible solvent, as an extension to the previous work by Paulsen and Renn [7] (who had demonstrated the capabilities of AJ for printing resistors mostly with resistance around $1 \mathrm{k} \Omega$ or higher).

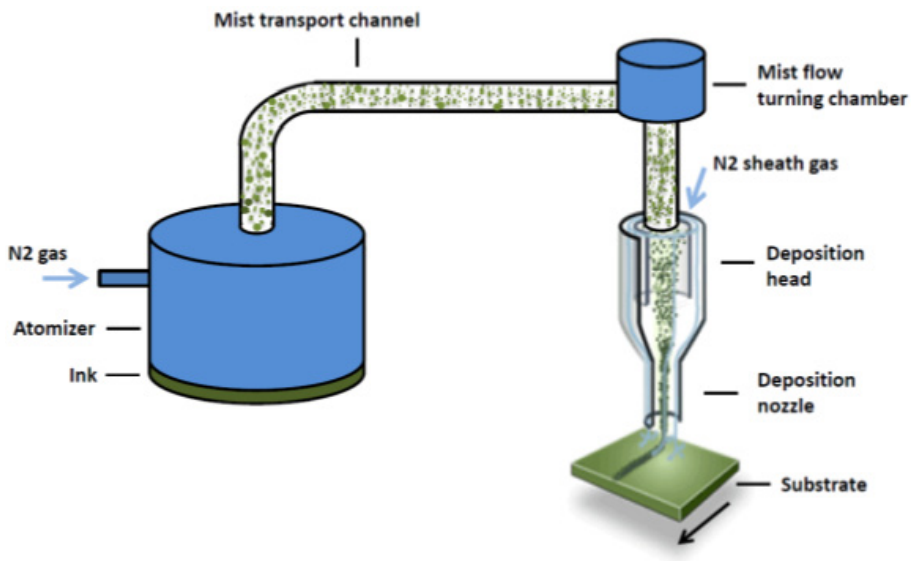

Figure 1. Schematics of the Aerosol Jet ${ }^{\circledR}$ direct-write system, consisting of an atomizer that generates mist of microdroplets of functional ink, and a mist transport-conditioning channel that delivers ink microdroplets to the deposition head, where a high-speed collimated mist jet is formed by an aerodynamic focusing nozzle with sheath gas to deposit ink material onto the substrate in a noncontact fashion

\section{INK MATERIAL PREPARATION}

Similar to the previous work [7], the PTF paste (TU-10S) used in this work was provided by Asahi Chemical Research Laboratory with the data sheet resistivity of $0.03 \Omega \mathrm{cm}$ (based on the sheet resistance of $15 \Omega /$ square / $20 \mu \mathrm{m}$ after sintered in convection oven at $150^{\circ} \mathrm{C}$ for 30 minutes). It consists of carbon and graphite powder uniformly dispersed in a thermosetting resin, with excellent adhesion to copper foil and behavior stability in environmental and highly accelerated stress screening (HASS) tests. However, AJ material deposition works well with ink droplets of diameters in the range between 1 and $5 \mu \mathrm{m}$ [6]. Any material that can be atomized into such kind of microdroplets can be printed with AJ process [8]. But the Asahi carbon paste for screen printing is not one of those materials readily suitable for AJ atomization. It must be diluted with a compatible solvent.

On the other hand, the Asahi TU-10S paste contains carbon nanoparticles with substantial amount of large graphite particles of sizes $>10 \mu \mathrm{m}$, which may not be carried in the atomized ink droplets of diameters $<5 \mu \mathrm{m}$ for AJ printing. If the ink cannot be atomized into microdroplets of all functional material components with consistent proportionalities, the ink properties would be expected to drift over time which makes development of repeatable, consistent process recipes difficult.

In this regard, the available Asahi PTF pastes may not be ideal for AJ printing. But we shall give it a due diligence evaluation.

Among several choices of diluting solvents, the ideal one should be volatile enough to enable fast in-flight evaporation of microdroplets [6] so that the footprint of printed features (such as the line width) would not vary significantly when the resistor cross-section-area is varied for adjusting the resistance value. For example, the diethylene glycol monoetyl ether (boiling point $=$ $202^{\circ} \mathrm{C}$, vapor pressure $=0.12 \mathrm{mmHg}$ at $20^{\circ} \mathrm{C}$ ), as one of the paste components, seems to be lack of volatility for effective in-flight microdroplet evaporation if used as the diluting solvent. Another paste solvent component, 1-butanol, has a reasonable volatility (boiling point $=117^{\circ} \mathrm{C}$, vapor pressure $=5 \mathrm{mmHg}$ at $20^{\circ} \mathrm{C}$ ), and the diluted ink prints reasonably well with the $\mathrm{AJ}$ pneumatic atomizer system when the substrate is heated to $60^{\circ} \mathrm{C}$ for ink evaporation enhancement.

\section{AEROSOL JET PRINTING \\ Process Parameters for Control of Resistance Value}

Even with solvent dilution of the paste (e.g., paste:butanol 4g:3ml which yields an ink with solid fraction about 33\%), the resultant ink is still quite viscous. Therefore, the pneumatic atomizer (PA) is used in the AJ system [6], where the mist density can be adjusted by varying the atomizer gas flow rate and/or the atomizer temperature. When the atomization process parameters are tuned properly for this particular ink, the mist density (ink mass carried in every cubic centimeter of mist volume) can be maintained at a constant value such that the rate of ink (solid) mass deposition $\mu$ becomes a controllable constant for a given mist flow rate through the ink deposition nozzle.

In the present work, a deposition nozzle of orifice diameter $\mathrm{D}=$ 
$0.3 \mathrm{~mm}$ is exclusively used, with a mist flow rate of $35 \mathrm{sccm}$ and a sheath of $70 \mathrm{sccm}$ (cf. Figure 1). Each resistor is printed in a form of line segment with a toolpath for back-and-forth relative motion between the deposition nozzle and substrate such that multiple stacked layers can be obtained. The amount of PTF ink material printed on each resistor can be controlled by print speed $u$ and number of stacked layers $N$ and a process recipe for consistent $\mu$. Ideally, it is expected that the resistance value of a printed resistor of a given pattern (e.g., a line with a cross-section area $\mathrm{A}$ of given length $\mathrm{L}$ ) is inversely proportional to the mass of the deposited ink material (or $\mathrm{N}$ at a fixed $\mathrm{u}$ ), as

$$
R=\rho \frac{L}{A}=\rho \frac{L u \rho_{m}}{N \mu}=f \frac{L u}{N},
$$

where $\mathrm{f}=\left(\rho \rho_{\mathrm{m}} / \mu\right)=\mathrm{R} \mathrm{N} /(\mathrm{L} \mathrm{u})$ with $\rho$ and $\rho_{\mathrm{m}}$ denoting the resistivity and mass density of sintered ink material. Consistent mass deposition rate $\mu$ translates to a consistent resistance value $\mathrm{R}$ of printed resistors. In practice, $\mathrm{N}$ and $\mathrm{u}$ are the two convenient printing process parameters for adjusting the value of $\mathrm{R}$ for a given print pattern (e.g., line segments of fixed L) with consistent $\mu$. Table 1 provides a summary of adjustable parameters for AJ printing PTF resistors with controllable resistance values.

Table 1. Parameters often used for producing a desired resistant value of AJ printed PTF resistors, with a given ink of constant (solid) mass density $\rho_{m}$ and resistivity $\rho$

\begin{tabular}{|c|l|}
\hline Parameter & \multicolumn{1}{c|}{ Description } \\
\hline Number of stack layers, $N$ & To flexibly adjust $A$ in (1), with a large range \\
\hline Print speed, $u(\mathrm{~mm} / \mathrm{s})$ & To adjust $A$ in $(1)$, within a limited range \\
\hline Mass deposition rate, $\mu(\mathrm{mg} / \mathrm{min})$ & Adjustable by varying PA flow rate, etc. \\
\hline Length of line segment, $L(\mathrm{~mm})$ & Variable defined by PCB design \\
\hline
\end{tabular}

With AJ printing, the printed feature size generally correlates with the deposition nozzle size, i.e., smaller nozzles are usually used for printing finer lines. For a given nozzle diameter, higher sheath-tomist flow rate ratio tends to produce narrower lines. There is an upper limit for the total (sheath plus mist) flow rate through a given nozzle size with a given standoff between nozzle and substrate, due to the requirement of steady laminar mist flow with an impinging jet $[6,9]$. Therefore, increasing the sheath-to-mist ratio for printing narrower lines would amount to compromising the mass output due to lower mist flow rate, for a fixed mist density generated from the atomizer. Thus, the sheath and mist flow rates with a given nozzle used in AJ printing has often been adjusted on case-by-case basis as well as ink-to-ink basis, with only qualitative guidelines available for meeting specific requirements in specific applications.

\section{To Maintain Consistent Ink Mass Output}

Because the ink is formulated to deliberately consist of a volatile component of solvents, the mist output from the atomizer inevitably carries (volatile) solvent vapor. To ensure consistent mass deposition rate $\mu$ in (1), the ink properties should be kept from changing with time which would not be possible with gradual loss of the volatile solvent. This fact leads to the need of compensating volatile solvent to the ink in the pneumatic atomizer reservoir at a rate matching the rate of solvent removal $\mathrm{Q}_{1}$ due to vapor carried out by mist output at a "dry" carrier gas flow rate Q, which may be estimated based on the ideal gas law as

$$
Q_{l}=\frac{n_{v} P_{v} M_{v}}{\rho_{v} \bar{R} T} \times Q,
$$

where $n_{v}$ denotes the mole fraction of the volatile component of solvents in the ink, $\mathrm{P}_{\mathrm{v}}(\mathrm{Pa})$ the absolute vapor pressure at temperature $\mathrm{T}$ and $\mathrm{M}_{\mathrm{v}}\left(\mathrm{kg} \mathrm{kmol}^{-1}\right.$ or $\left.\mathrm{g} \mathrm{mol}^{-1}\right)$ the molecular weight of the volatile component of solvents, while $\rho_{\mathrm{v}}\left(\mathrm{kg} \mathrm{m}^{-3}\right)$ is the liquid density of the volatile solvent and $\overline{\mathrm{R}}$ the universal gas constant $\left(=8.3143 \mathrm{~J} \mathrm{deg}^{-1} \mathrm{~mol}^{-1}\right)$. Using the 1 -butanol as an example $\left(\mathrm{P}_{\mathrm{v}}=\right.$ $5 \mathrm{mmHg}, \mathrm{M}_{\mathrm{v}}=74.12, \rho_{\mathrm{v}}=0.81 \mathrm{~g} / \mathrm{cc}$ ), we estimate the needed solvent compensation rate $\mathrm{Q}_{1} \sim 1.5 \mathrm{~mL} /$ hour for $\mathrm{Q}=1000 \mathrm{sccm}$ and $\mathrm{n}_{\mathrm{v}}=1$ according to (2).

It should be noted that (2) is at best an approximating equation to reality, based on Raoult's law for vapor pressure of a mixture of liquid with non-interactive components and assumption of saturated vapor in carrier gas. Accurate control of volatile solvent fraction in an ink almost always takes a few iterations of trialand-error adjustment of solvent compensation rate $Q_{1}$ with (2) providing an initial guess. The solvent compensation rate $\mathrm{Q}_{1}$ can be practically controlled either by injecting liquid solvent (e.g., with a syringe pump) or by loading solvent vapor into the carrier gas through an upstream bubbler with a controlled temperature.

\section{Calibration of Process Parameters}

With AJ printing, the mass deposition rate $\mu$ can usually be measured by weighing the amount of deposited mass in a known time interval, and the consistency of $\mu$ can be evaluated by examining the measured values of $\mu$ at different print time intervals. According to (1) with fixed $\mathrm{u}$ and $\mathrm{N}$, consistent $\mu$ is equivalent to consistent $\mathrm{R}$. Therefore, in this work we mainly measure the values of $\mathrm{R}$ from a nominal resistance test pattern (shown in Figure 2) printed on glass slides at fixed $\mathrm{u}$ and $\mathrm{N}$ to evaluate the consistency of $\mu$.

For example, in a printing test for over an hour we measured the value of $\mu$ (by the gravimetric analysis of cured amount of ink printed for 10 minutes) at four different time points (e.g., about 20 minutes apart) as $0.15,0.13,0.14,0.14 \mathrm{mg} / \mathrm{min}$ which corresponds to "percent relative standard deviation" $\% \mathrm{RSD}=5.8$. We also printed test patterns at three different time points (about 20 minutes apart) and measured value of $\mathrm{R}$ as $6.56,6.75,6.76 \mathrm{k} \Omega$ with corresponding $\% \mathrm{RSD}=1.7,0.3,1.3$. The overall average value of $\mathrm{R}=6.69 \mathrm{k} \Omega$ with $\% \mathrm{RSD}=1.8$ for all measured samples $(\mathrm{n}=9)$. Thus, we believe this set of print test has a consistent $\mu$ based on the consistent value of $\mathrm{R}$ as indicated by the tight $\% \mathrm{RSD}$. 


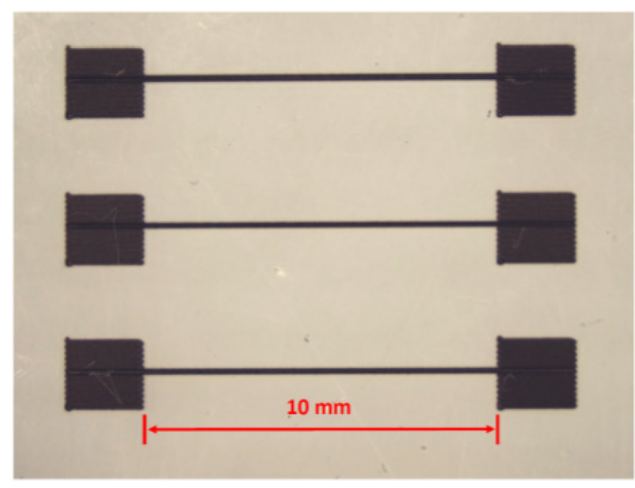

Figure 2. Aerosol Jet ${ }^{\oplus}$ printed resistance test pattern of $10 \mathrm{~mm}$ long lines with $2 \times 2 \mathrm{~mm}^{2}$ probe pads at ends on a glass slide. Here, the lines have width $<0.25 \mathrm{~mm}$

Another reason for relying on the resistance measurement, instead of the gravimetric analysis, to evaluate consistency of $\mu$ is due to the difficulty in accurately measuring the weight of deposited ink mass with a typical analytical precision balance. When the balance resolution is at the level of $0.1 \mathrm{mg}$ (e.g., Mettler Toledo AB54-S available in our laboratory), the accuracy of any measured weight below $1 \mathrm{mg}$ becomes questionable. If the value of $\mu$ is below 1.0 $\mathrm{mg} / \mathrm{min}$, it will require collecting the printed ink mass for more than 10 minutes to obtain a meaningful reading from the balance, whereas printing a line-pad pattern with $\mathrm{N}>10$ at $\mathrm{u}=10$ or 5 $\mathrm{mm} / \mathrm{s}$ only takes about 1 or 2 minutes. After all, the consistency of resistance value of printed lines is of our primary concern here.

\section{RESULTS}

\section{Characteristics of Printed Ink}

With $\mu=0.14 \mathrm{mg} / \mathrm{min}$, a profilometer measurement yields $\mathrm{A}$ $=2.37 \times 10^{-3} \mathrm{~mm}^{2}(\% \mathrm{RSD}=1.8$ with $\mathrm{n}=9$ samples $)$ for the lines printed at $\mathrm{u}=10 \mathrm{~mm} / \mathrm{s}$ with $\mathrm{N}=12$ over an hour at three different times. Thus, the mass density of cured ink $\rho_{\mathrm{m}}$ is determined as $0.14 \times 12 /\left(60 \times 10 \times 2.37 \times 10^{-3}\right)=1.18 \mathrm{~g} / \mathrm{cc}$. From the measured resistance value $\mathrm{R}=6.69 \mathrm{k} \Omega(\% \mathrm{RSD}=1.8$ for $\mathrm{n}=9)$ for the lines of $\mathrm{L}=10 \mathrm{~mm}$ sintered at $200^{\circ} \mathrm{C}$ for 30 minutes, the value of resistivity $\rho$ is determined according to (1) as $6.69 \times 2.37 \times 0.1 / 10=$ $0.159 \Omega \mathrm{cm}$ (which is more than five times $0.03 \Omega \mathrm{cm}$ as the Asahi data indicated for the paste). Thus, we have $\mathrm{f}=\mathrm{R} \mathrm{N} /(\mathrm{L} \mathrm{u})=$ $6.69 \times 10^{3} \times 12 /(10 \times 10)=802.8 \Omega \mathrm{s} / \mathrm{mm}^{2}$ in (1) for this particular printing process.

Although it was suggested in the Asahi data sheet to sinter the paste in convection oven at $150^{\circ} \mathrm{C}$ for 30 minutes, we found the resistance value of $\mathrm{AJ}$ printed lines $\mathrm{R}$ can decrease about $8 \%$ by increasing the sintering time from 0.5 hours to 1.5 hours baking in an oven at $150^{\circ} \mathrm{C}$. When baked for 0.5 hours at $200^{\circ} \mathrm{C}$ the value of $\mathrm{R}$ can decrease about $25 \%$ from that at $150^{\circ} \mathrm{C}$ (for the same duration). At $200^{\circ} \mathrm{C}$ increasing from 0.5 hours to 1.5 hours and 16 hours yields reduced $\mathrm{R}$ by about $3 \%$ and $12 \%$, respectively. Thus, the resistance value of printed PTF resistors can also be adjusted by varying the sintering temperature and duration. In other words, the sintering temperature and duration also become the process recipe parameters that need to be specified for production. In the present work, all the samples are sintered at $200^{\circ} \mathrm{C}$ for 30 minutes for simplicity.

\section{AJ Printed PTF Resistors}

With the available PCBs of black FR-4 having abundant arrays of constant $0.64 \mathrm{~mm}$ gaps between gold coated copper pads, we can print resistors of $\mathrm{L}=0.64 \mathrm{~mm}$ across the gaps between contact pads (shown in Figure 3) for evaluation of AJ capabilities as well as challenges. Here the lines are printed a $2 \mathrm{~mm}$ long line segment with back-and-forth toolpath set according to a given number of layers $\mathrm{N}$ at a given speed $\mathrm{u}$. Using the back-and-forth printing toolpath can produce resistors of minimum footprint line width. Before printing all substrates are cleaned by wiping with an alcohol (such as $\mathrm{MeOH}, \mathrm{EtOH}$, or IPA) Because our previous work has demonstrated the AJ capabilities for printing resistors mostly of $\mathrm{R}>1 \mathrm{k} \Omega$ (with lowest $\mathrm{R} \sim 0.7 \mathrm{k} \Omega$ ), our focus here is on printing resistors of $\mathrm{R}$ around $100 \Omega$ for $\mathrm{L} \sim 1 \mathrm{~mm}$. The main challenge for printing the $100 \Omega$ resistors using a similar type of ink is to stack up lines with substantial pile height $(>50 \mu \mathrm{m})$ without significantly increasing the line width (e.g., 0.2 to $0.3 \mathrm{~mm}$ ), to retain a small resistor footprint.

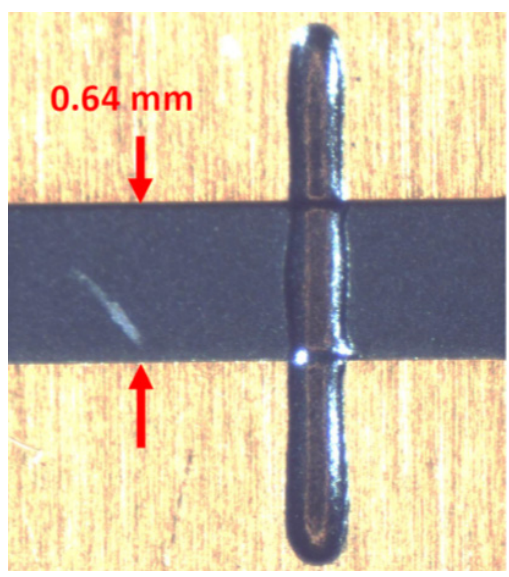

Figure 3. Aerosol Jet ${ }^{\oplus}$ printed $100 \Omega$ resistor of line width about 0.3 $\mathrm{mm}$ and $A \sim 1.27 \times 10^{-2} \mathrm{~mm}^{2}$ across a $0.64 \mathrm{~mm}$ gap between gold coated copper pads on black FR-4 PCB (having a comparable dimension of the metric 0603 standard surface mount resistors)

Using the printing process of $\mathrm{f}=802.8 \Omega \mathrm{s} / \mathrm{mm}^{2}$ we have (1) become $\mathrm{R}=513.79 \times(\mathrm{u} / \mathrm{N})$ predicting the resistance values of $\mathrm{L}$ $=0.64 \mathrm{~mm}$ resistors for $\mathrm{N}=8,16,24$, and 32 at $\mathrm{u}=10$ and $5 \mathrm{~mm} / \mathrm{s}$ in Table 2 as a reference for discussion.

Table 2. Theoretically predicted resistance values of $L=0.64 \mathrm{~mm}$ resistors by (1) for the $f=802.8 \Omega \mathrm{s} / \mathrm{mm} 2$ printing process

\begin{tabular}{r|c|c|c|c}
\hline$N$ & 8 & 16 & 24 & 32 \\
\hline \hline$u(\mathrm{~mm} / \mathrm{s})$ & \multicolumn{5}{|c}{10} \\
\hline$R(\mathrm{ohm})$ & 642.24 & 321.12 & 214.08 & 160.56 \\
\hline$u(\mathrm{~mm} / \mathrm{s})$ & \multicolumn{5}{|c}{5} \\
\hline$R(\mathrm{ohm})$ & 321.12 & 160.56 & 107.04 & 80.28 \\
\hline
\end{tabular}


However, the measured resistance values of those $\mathrm{L}=0.64 \mathrm{~mm}$ resistors actually printed across the PCB contact pads shown in Table 3 do not exactly match the corresponding values in Table 2, though they follow a similar trend with somewhat "agreement" in a rough sense. The discrepancy becomes more severe with increasing $\mathrm{N}$. For example, at $\mathrm{N}=32$, the measured resistance values may deviate from the theoretical ones in Table 2 by up to $30 \%$.

Table 3. Measured resistance values of printed $L=0.64 \mathrm{~mm}$ resistors across the PCB contact pads with the $f=802.8 \Omega \mathrm{s} / \mathrm{mm} 2$ printing process

\begin{tabular}{|r|c|c|c|c|}
\hline$N$ & 8 & 16 & 24 & 32 \\
\hline \hline$u(\mathrm{~mm} / \mathrm{s})$ & \multicolumn{5}{|c}{10} \\
\hline$R(\mathrm{ohm})$ & 612.31 & 344.29 & 246.05 & 196.59 \\
\hline$\% \mathrm{RSD})$ & 2.90 & 3.05 & 2.17 & 1.08 \\
\hline$u(\mathrm{~mm} / \mathrm{s})$ & \multicolumn{5}{|c}{5} \\
\hline$R(\mathrm{ohm})$ & 319.66 & 181.98 & 132.50 & 105.13 \\
\hline$\% \mathrm{RSD}$ & 2.94 & 1.58 & 1.51 & 1.53 \\
\hline
\end{tabular}

Figure 4 also shows noticeable deviation of Table 3 data from the theoretical line, although they seem fairly close (but may not be close enough for required precision in the present application). The fitted line has a different slope and nonzero intercept for the actual data, while the theoretical line has a steeper slope with zero intercept. Positive intercept is expected especially for inks printed on the FR-4 surfaces with roughness, because some portion of the printed ink material is for filling the surface depressions rather than contributing to the electrical conduction. With a positive intercept and deviation from the theoretical line, the actual resistance values of printed resistors do not exactly follow the proportionality rule to the value of $\mathrm{L} \mathrm{u} / \mathrm{N}$. For example, the resistance values for $\mathrm{N}=$ 16 or 32 are not simply half of those for $\mathrm{N}=8$ or 16 at a given $\mathrm{u}$ in Table 3, unlike that shown in Table 2 according to the (idealized) theory.

On the other hand, the theoretical formula is derived for an ideal line of uniform cross-section area A, whereas the actual printed line must go over the edges of contact pads which has a step height about $25 \mu \mathrm{m}$ (on the test PCB) resulting in some nonuniformity of the printed line cross-section area, as might be expected from rather complex local effects of capillary action on wet ink. The induced flow and movement of deposited (wet) ink due to capillary action as well as aerodynamic stresses from the impinging jet can also be influenced by the dynamics of solvent evaporation in deposited ink which depends on the toolpath design of time intervals between each pass of printing. In fact, the printed line shown in figure 3 of width about $0.3 \mathrm{~mm}$ indeed shows visible step marks at the contact pad edges even with a pile height more than $50 \mu \mathrm{m}$.

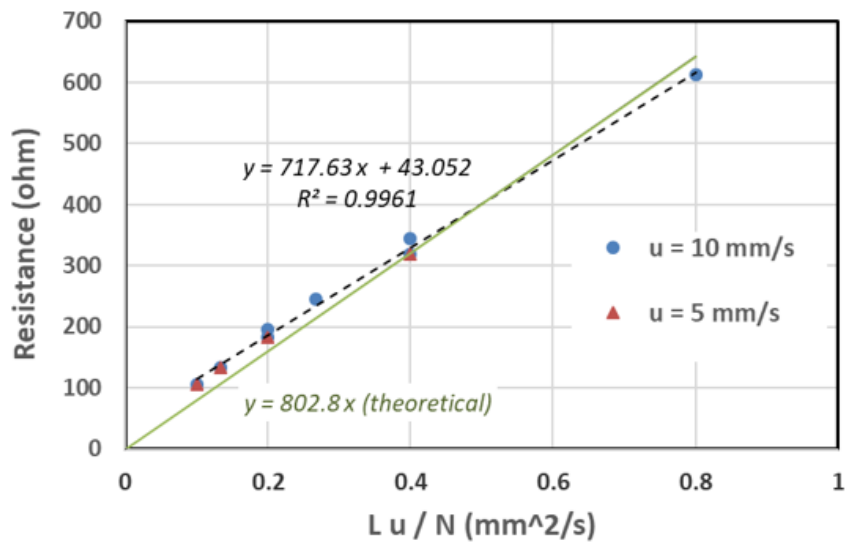

Figure 4. Resistance $R$ versus $L \mathrm{u} / \mathrm{N}$ based on data in Table 3

Moreover, the print speed $\mathrm{u}$ as set in the toolpath may not be the actual relative motion velocity magnitude between the AJ nozzle and substrate during the back-and-forth movement for "short line" PTF resistor printing, depending upon the motion quality of the stage and its acceleration timescale. Therefore, the calibration process with the test pattern on glass slide in Figure 2 may only provide a rough guideline for further fine-tuning the process parameters such as $\mathrm{N}$ and $\mathrm{u}$ with a given $\mu$ at best if high precision resistors are to be printed.

Unless a high-precision motion system (which could be rather costly) is used, printing resistors at $u>10 \mathrm{~mm} / \mathrm{s}$ may not be easy to control due to the stage acceleration and motion accuracy challenges. To avoid confounding effects from several variables, it is preferred to keep the print speed $\mathrm{u}$ fixed (e.g., $\mathrm{u}=10 \mathrm{~mm} / \mathrm{s}$ ) and use the number of layers $\mathrm{N}$ as the main adjustment parameter for a given target resistance value. Then, it would be desirable to have $\mathrm{N}$ large enough (e.g., > 20) for the target resistance value such that changing $\mathrm{N}$ by 1 or 2 can adjust printed resistance value $\mathrm{R}$ by no more than a few percent for fine tuning. Of course, keeping $\mathrm{N}$ at a fixed value and adjusting u can also yield a fine-tuned value of resistance.

With given ranges of $\mathrm{N}$ and $\mathrm{u}$ for a target resistance value, we can also set an appropriate printing process for a desirable mass deposition rate $\mu$ by varying the AJ pneumatic atomization gas flow rate $Q$. As an example, we could obtain a greater $\mu$ by simply increasing the atomization gas flow rate $Q$ in another experiment for printing resistors of lower resistance values. In this case, we have the measured resistance value $\mathrm{R}=3.00 \mathrm{k} \Omega(\% \mathrm{RSD}=1.8$ for $\mathrm{n}=12$ over 60 minutes) for the lines of $\mathrm{L}=10 \mathrm{~mm}$ in the same test pattern shown in Figure 2 with $\mathrm{N}=12$ and $\mathrm{u}=10 \mathrm{~mm} / \mathrm{s}$. This leads to $\mathrm{f}=360.2 \Omega \mathrm{s} / \mathrm{mm}^{2}$ (lower than the previous case of $\mathrm{f}=$ $802.8 \Omega \mathrm{s} / \mathrm{mm} 2$ by a factor of 0.449$)$.

With an interest in printing $100 \Omega$ PTF resistors across a gap $\sim 1$ $\mathrm{mm}$ between contact pads on the FR-4 PCB, we want to explore the parameter space for $\mathrm{N}$ and $\mathrm{L}$ with $\mathrm{u}=10 \mathrm{~mm} / \mathrm{s}$. According to the (rough) calibration value of $\mathrm{f}=360.2 \Omega \mathrm{s} / \mathrm{mm}^{2}$ we obtain $\mathrm{N} \sim 36$ for $\mathrm{L}=1.0 \mathrm{~mm}$ and $\mathrm{u}=10 \mathrm{~mm} / \mathrm{s}$ from (1) as a theoretical estimate. With expected deviation from idealized theory (shown in figure 4), an experiment with $\mathrm{N}=24$ and 48 is performed for $\mathrm{L}=1.0,0.64$, and $0.5 \mathrm{~mm}$ at $\mathrm{u}=10 \mathrm{~mm} / \mathrm{s}$. The results are shown in Table 4. 
Table 4. Measured resistance values of printed $L=1.0,0.64$, and 0.5 $\mathrm{mm}$ resistors across the РCB contact pads with the $\mathrm{f}=360.2 \Omega \mathrm{s} / \mathrm{mm}^{2}$ printing process at $u=10 \mathrm{~mm} / \mathrm{s}$

\begin{tabular}{|r|c|c|c|}
\hline$L(\mathrm{~mm})$ & 1.0 & 0.64 & 0.5 \\
\hline \hline$N$ & \multicolumn{3}{|c|}{24} \\
\hline$R$ (ohm) & 124.79 & 81.17 & 60.90 \\
\hline$\% \mathrm{RSD}$ & 2.76 & 3.13 & 6.22 \\
\hline$N$ & \multicolumn{3}{|c}{48} \\
\hline$R$ (ohm) & 68.24 & 45.93 & 35.94 \\
\hline$\% \mathrm{RSD}$ & 2.73 & 1.53 & 4.43 \\
\hline
\end{tabular}

Not surprisingly, the measured resistance values in Table 3 do not exactly match the theoretical values predicted by (1) which suggests $150.08,96.05,75.04 \Omega$ for $\mathrm{L}=1.0,0.64,0.5 \mathrm{~mm}$ with $\mathrm{N}=24$ at $\mathrm{u}=$ $10 \mathrm{~mm} / \mathrm{s}$. If all the data points of resistance at $\mathrm{N}=24$ and 48 for $\mathrm{L}$ $=1.0,0.64,0.5 \mathrm{~mm}$ are used to fit a line for $\mathrm{u}=10 \mathrm{~mm} / \mathrm{s}$, we have

$$
R=2816.50 \frac{L}{N}+6.7082 .
$$

For $\mathrm{R}=100 \Omega$ and $\mathrm{L}=1.0 \mathrm{~mm}$, (3) predicts $\mathrm{N}=2816.50 /(100$ $-6.7082)=30.19$, or $\mathrm{R}=100.6 \Omega$ for $\mathrm{N}=30$. We then carried out another experiment to print several resistors of $\mathrm{L}=1.0 \mathrm{~mm}$ at $\mathrm{u}=10 \mathrm{~mm} / \mathrm{s}$ with $\mathrm{N}=32$ and 48 , and obtained $\mathrm{R}=105.4 \Omega$ $(\% \mathrm{RSD}=2.6)$ and $68.1 \Omega(\% \mathrm{RSD}=2.8)$, while $(3)$ predicts $94.7 \Omega$ and $65.4 \Omega$, respectively. In this case, the AJ printing process might drift slightly from the calibrated values, when with an ink material not being optimized. Once an optimized ink is made available, the AJ process can become quite consistent and repeatable, as has been demonstrated with several industrial production applications.

Based on the present result for resistors of $\mathrm{R}=100 \Omega$ with printed $2 \mathrm{~mm}$ long line segment at $\mathrm{u}=10 \mathrm{~mm} / \mathrm{s}$ and $\mathrm{N}=32$, each resistor is estimated to take about $6.4 \mathrm{~s}(=2 \times 32 / 10)$ to print. This is roughly applicable to the case of a large PCS with multiple resistors, because the AJ print head typically moves very fast (e.g., at a speed of $>50 \mathrm{~mm} / \mathrm{s}$ ) from one resistor location to another.

As the AJ printed PTF resistors $(\mathrm{R}<100 \Omega, \mathrm{L}=1.0 \mathrm{~mm}$, with $>60 \mu \mathrm{m}$ pile heights) were measured after exposed to "damp heat test" at $85 \% \mathrm{RH}$ and $85^{\circ} \mathrm{C}$ in a climate chamber for 250 hours, the resistance values appear to increase only by about $2 \%$. After more than one hundred thermal cycling of $-65^{\circ} \mathrm{C}$ to $150^{\circ} \mathrm{C}$, the resistance values seemed to change less than $1 \%$ which was more likely due to measurement errors. Hence, those AJ printed resistors are very robust even under extreme environmental conditions.

The temperature sensitivity of $\mathrm{AJ}$ printed resistors were also evaluated in a range of temperatures from $20^{\circ} \mathrm{C}$ to $60^{\circ} \mathrm{C}$. With the resistance value $\mathrm{R}$ at $20^{\circ} \mathrm{C}$ set as $\mathrm{R}_{0}$, the measured data of $\Delta \mathrm{R} / \mathrm{R}_{0}$ $=\left(\mathrm{R}-\mathrm{R}_{0}\right) / \mathrm{R}_{0}$ versus temperature $\mathrm{T}$ can be fitted to a line with a slope of $\left(1 / \mathrm{R}_{0}\right) \Delta \mathrm{R} / \Delta \mathrm{T}=-8.7 \times 10^{-4}$. Thus, the temperature coefficient of resistance (TCR) of AJ printed resistors is as expected for a carbon ink, indicating that $\mathrm{R}$ may change by less than $1 \%$ from its nominal value for a temperature variation of $\Delta \mathrm{T} \sim 10^{\circ} \mathrm{C}$.

\section{CONCLUSIONS}

With an ink made by diluting a PTF paste (Asahi TU-10S for screen printing) with 1-butanol, we are able to use the Aerosol Jet ${ }^{\circledR}$ system to print resistors directly onto PCBs with lines of width about $0.3 \mathrm{~mm}$ or less across gaps of different sizes between contact pads. The resistance value of AJ printed resistors can have quite high precision, typically with the relative standard deviation $\%$ RSD $<5$. But some efforts may be needed to properly calibrate and fine tune the process parameters, to produce desired accuracy against a target resistance value.

Through several experiments, we have demonstrated feasible methods for adjusting the resistance value of printed resistors by varying the speed $\mathrm{u}$ and number of stacked layers $\mathrm{N}$ for a given gap size L between contact pads. Moreover, the mass deposition rate $\mu$ can also be changed as an additional adjustment "knob" in the AJ process by changing the gas flow rate for pneumatic atomization (or the atomizer temperature [7]). While the theoretical formula (1), based on idealized line of uniform cross section, can be useful for a rough estimate, fine tuning the process parameters with experimental data is usually necessary for desired accuracy to print precision resistors.

One of the advantages with using AJ to print PTF resistors is the small footprint of lines with substantial pile height. This is enabled by the unique capability of AJ process that allows in-flight solvent evaporation of the ink microdroplets such that the ink can be deposited with fairly high solid contents in a "semi-dry" state [6]. Figure 5 shows the images of two printed resistors across a gap of $\mathrm{L}=1.0 \mathrm{~mm}$ between contact pads on a FR4 PCB. The one with $\mathrm{R}$ $\sim 900 \Omega$ has a line width about $150 \mu \mathrm{m}$ and peak height about 10 $\mu \mathrm{m}$ (with the line profile shown in Figure 6), while line width of the $\mathrm{R} \sim 100 \Omega$ one becomes about $300 \mu \mathrm{m}$ with a pile height $>60 \mu \mathrm{m}$.

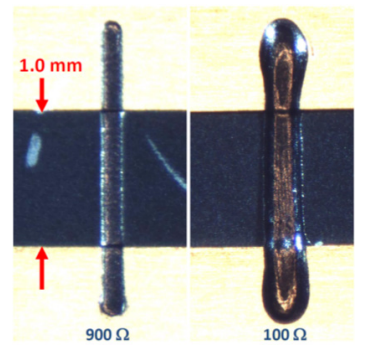

Figure 5. Aerosol Jet ${ }^{\oplus}$ printed resistors of $900 \Omega$ and $100 \Omega$ with line width about $0.15 \mathrm{~mm}$ and $0.3 \mathrm{~mm}$ acrossa $1.0 \mathrm{~mm}$ gap between gold coated copper pads on black FR-4 PCB

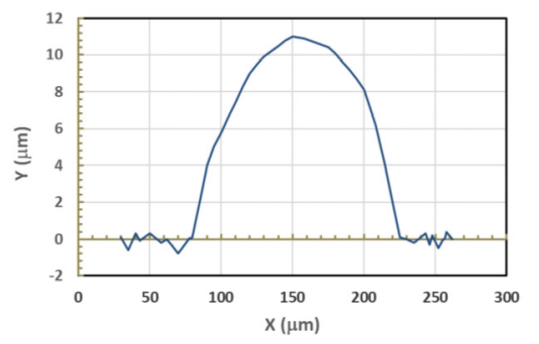

Figure 6. Line profile of the AJ printed resistor of $900 \Omega$ (left image in Figure 5) measured with a Dektak profilometer (line width $~ 150 \mu \mathrm{m}$, $A \sim 1.16 \times 10^{-3} \mathrm{~mm}^{2}$ ) 
Because the resistance of a given line resistor is inversely proportional to the line cross-section-area $A$ in (1), the printed resistors of lower resistance values demand larger $\mathrm{A}$ corresponding to wider lines and/or higher pile heights. With the back-and-forth toolpath, however, the line width of AJ printed $68 \Omega$ resistors (for $\mathrm{L}$ $=1.0 \mathrm{~mm}$ with $\mathrm{N}=48$ in Table 3) do not seem to increase further from that of $100 \Omega$ resistors (shown in Figure 5), corresponding to a significant increase of the pile height to about $90 \mu \mathrm{m}$. If the same ink is used to print resistors of $\mathrm{R} \sim 300 \Omega$ or $>500 \Omega$ (for $\mathrm{L}=1.0$ $\mathrm{mm}$ ), the line width usually becomes $\sim 200 \mu \mathrm{m}$ or $150 \mu \mathrm{m}$ (using a deposition nozzle of orifice diameter $\mathrm{D}=0.3 \mathrm{~mm}$ ). So, narrower lines (or smaller footprint) can be much easier to produce when the target resistance value becomes relatively large (e.g., $>1 \mathrm{k} \Omega$ ).

If a narrower line becomes desirable, we can print (low resistance) resistors with smaller length $\mathrm{L}$ with reduced $\mathrm{N}$ as suggested by (3) for limited pile height. However, it should be kept in mind that reducing $\mathrm{L}$ may lead to higher \%RSD (cf. Table 3 and previous discussion by Paulsen and Renn [7]), probably due to relatively more significant influence of end effects at the contact pad edges.

In this work we have mentioned quite a few factors that could influence the resistance value of AJ printed PTF resistors. Some of them are important to pay attention to during the early exploratory stage of research, while a few of them become the key AJ process parameters for fine tuning the resistance value. For example, the ink formulation with proper solvent choice and particle size can play a determinant role in AJ printing performance, such as maintaining a consistent mass output, appropriate solvent evaporation rate for line height stacking and printed pattern quality control, etc. The quality of motion stage can also be important because the accuracy of print speed directly influence the accuracy of the resistance value of printed resistors, as shown in (1).

Once the selections of ink formulation and motion equipment have been decided, the key parameters for AJ process development are the mass deposition rate $\mu$, print speed $\mathrm{u}$, and number of stacked layer $\mathrm{N}$ for controlling the resistance value $\mathrm{R}$ in a given printed resistor geometry (such as a line segment of length $\mathrm{L}$ ). As exemplified in our case of printing the $100 \Omega$ resistors, the AJ printing process development may require a few progressive levels of calibrations. The first level of calibration may involve varying all those three variables $(\mu, \mathrm{u}$, and $\mathrm{N}$ ), to balance the requirements of productivity and print quality for a target resistance value in a given resistor geometry. The final fine-tuning in our case is done by varying only one variable, i.e., the number of stacked layer $\mathrm{N}$ (which is desired to be large, e.g., $\mathrm{N}>20$, for incremental fine resolution adjustment). It can also be done by using the print speed $\mathrm{u}$ if the motion stage is of reasonably high quality. In general, most variables should have their values locked in when performing the final fine-tuning by varying only one variable.

\section{FUTURE WORK}

As noted earlier, there is definitely room for improvement on the PTF ink formulations. The Asahi carbon paste used in this work was originally developed for screen printing without consideration of the droplet sizes in AJ printing. The screen printing pastes usually contain functional material particles of larger sizes (e.g., > $10 \mu \mathrm{m}$ ) than that desired for AJ inks (with particles $<0.1 \mu \mathrm{m}$ ) to allow atomized microdroplets (of diameters $<5 \mu \mathrm{m}$ ) to carry. The lack of those large graphite particles in AJ deposited ink could be the main reason for higher resistivity of AJ printed resistors than the Asahi data sheet value based on screen printing test.

Therefore, significantly reducing the graphite particle sizes would make the PTF inks more suitable for AJ printing. Once the graphite particles become small enough for the atomized microdroplets to carry, the AJ deposited ink is expected to have comparable resistivity to that of screen printed paste. This could allow printing similar resistors with potentially five times less cross-section-area with narrower lines.

Although the diluting solvent (1-butanol) for the resistive paste in this work is commonly used in $\mathrm{AJ}$ inks, it still seems not volatile enough for the present application of printing high aspect-ratio resistors with substantial pile heights, without heating the substrate. A solvent with higher volatility may be more desirable when formulating new PTF inks for easier stacking up the line height without increasing the line width in AJ printing.

On the AJ process side, research for fundamental understanding of the ink-substrate wetting behavior can be helpful to guide detailed calibration of the tuning parameters. The effects of ink evaporation on the printed line cross-section geometry due to toolpath design differences, i.e., time intervals between printing stacked layers, were observed but not thoroughly investigated. Further examinations can be time-consuming, but may lead to explanations for sources of the uncertainties in AJ printed resistors and, more importantly, offer means for controlling and reducing resistance deviations from the target value. In general, the AJ process allows adjustment and finetuning of the print outcome with multiple parameters. To harness the effects of each parameter for gaining predictive knowledge often takes patience and persistent efforts.

\section{ACKNOWLEDGEMENTS}

The authors would like to thank Asahi Chemical Research Laboratory for generously providing us the trial TU-10S carbon paste. The frequent helps from Justin Bourassa and Mathew Schrandt are highly appreciated.

\section{REFERENCES}

[1] J. Rector, "Economic and technical viability of integral passives", Proceedings of 4th International Symposium and exhibition on Advanced Packaging Materials, 1998, pp. 277-283

[2] A. E. Ostfeld, I. Deckman, A. M. Gaikwad, C. M. Lochner, and A. C. Arias, "Screen printed passive components for flexible power electronics”, Scientific Reports Vol. 5, 2015, 15959

[3] A. Y. Xiao, Q. K. Tong, and A. C. Savoca, "Polymer-thick film materials for integral resistors", Proceedings of 49th Electronic Components and Technology Conference, 1999, pp. 88-92

[4] https://www.fespa.com/en/news-media/industry/thefuture-of-screen-printing 
[5] M. J. Renn, G. H. Marquez, B. H. King, M. Essien, and W. D. Miller, "Flow- and laser-guided direct write of electronic and biological components", in Direct-Write Technologies for Rapid Prototyping Applications: Sensors, Electronics, and Integrated Power Sources (A. Pique and D. B. Chrisey, eds), Academic Press, San Diego, CA, 2002, pp. 475-492

[6] J. Q. Feng and M. J. Renn, "Aerosol Jet ${ }^{\circledR}$ direct-write for microscale additive manufacturing", Journal of Micro- and NanoManufacturing, vol. 7(1), 2019, 011004

[7] J. A. Paulsen and M. J. Renn, "Maskless printing of miniature polymer thick film resistors for embedded applications", IPC 3rd International Conference on Embedded Technology, Chelmsford, MA, 2 May 2006 https://www.optomec.com/wp-content/ uploads/2014/04/Optomec_Maskless_Printing_of_Resistors_ for_Embedded_Applications.pdf

[8] N. J. Wilkinson, M. A. A. Smith, R. W. Kay, and R. A. Harris, "A review of aerosol jet printing---a non-traditional hybrid process for micro-manufacturing", International Journal of Advanced Manufacturing Technology, 2019, https://doi. org/10.1007/s00170-019-03438-2

[9] J. Q. Feng, "Mist flow visualization for round jets in Aerosol Jet ${ }^{\circledR}$ printing”, Aerosol Science and Technology, vol. 53(1), 2019, 45-52 https://doi.org/10.1080/02786826.2018.1532566

\section{BIOGRAPHIES}

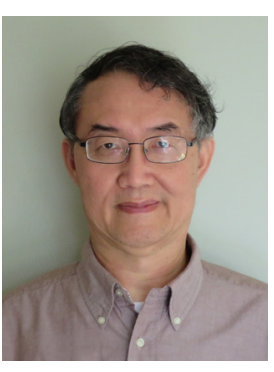

Dr. James Q. Feng is a Principal Engineer of Optomec, with an extensive $R \& D$ experience in precision material placement technologies. He graduated from Tsinghua University in Beijing, before pursuing his $\mathrm{PhD}$ degree at University of Illinois at Urbana-Champaign in the United States. After a few years of postdoctoral researches at University of Minnesota and Oak Ridge National Laboratory, Dr. Feng had worked at various industrial companies such as Xerox Corporation, Clear Science Corp, and Boston Scientific Corporation, prior to joining Optomec, Inc. Over years, he has published more than 60 peerreviewed journal articles and holds more than 20 U.S. Patents.

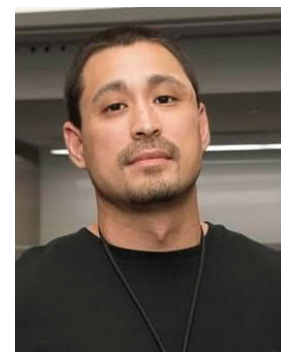

Anthony Loveland is an experienced specialist in semiconductor equipment and processes, with broadened expertise in additive manufacturing and materials engineering. He holds a BS degree in electronic engineering technology, and worked with multiple additive manufacturing technologies in several $R \& D$ organizations of DOE laboratories, on fabrication of hybrid material structures for sensing applications. During the time of working at Optomec, he gained skills in Aerosol Jet ${ }^{\circledR}$ direct-write applications for printed electronics as well as related ink material formulations, while developing equipment for reliability testing of printed electronics. To further his ambition in utilizing multiple additive manufacturing technologies to produce the next generation flexible hybrid electronics for applications in neuroscience and IOT, he has joined Advanced \& Exploratory Systems at Sandia National Laboratories, currently as a Principal Technologist.

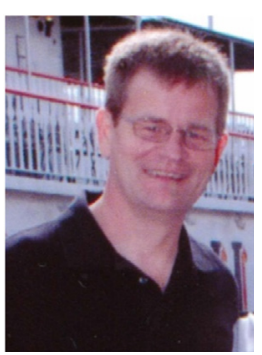

As the CTO of Optomec, Dr. Michael J. Renn is a recognized expert in the development of Aerosol Jet ${ }^{\circledR}$ technology and its applications in various industries and research organizations. Prior to joining Optomec in 1999, Dr. Renn worked at the University of Colorado's JILA Institute as a postdoctoral fellow, and became a faculty member at Michigan Technological University where he was the principal investigator on a DARPA-MICE project that launched the Aerosol Jet ${ }^{\circledR}$ technology development. Since then he has been directing the Optomec Advanced Applications Laboratory in St. Paul, MN. Dr. Renn holds more than 20 issued and pending patents. He has published more than 30 journal articles. 